\title{
ARTICLE
}

\section{Interaction between noradrenergic and cholinergic signaling in amygdala regulates anxiety- and depression-related behaviors in mice}

\author{
Yann S. Mineur ${ }^{1}$, Emma L. Cahuzac ${ }^{1}$, Tenna N. Mose ${ }^{1}$, Matthew P. Bentham ${ }^{1}$, Margreet E. Plantenga ${ }^{1}$, \\ David C. Thompson ${ }^{1}$ and Marina R. Picciotto (D)
}

\begin{abstract}
Medications that target the noradrenergic system are important therapeutics for depression and anxiety disorders. More recently, clinical studies have shown that the a2-noradrenergic receptor (a2AR) agonist guanfacine can decrease stress-induced smoking relapse during acute abstinence, suggesting that targeting the noradrenergic system may aid in smoking cessation through effects on stress pathways in the brain. Acetylcholine $(A C h)$, like the nicotine in tobacco, acts at nicotinic acetylcholine receptors (nAChRs) to regulate behaviors related to anxiety and depression. We therefore investigated interactions between guanfacine and $A C h$ signaling in tests of anxiolytic and antidepressant efficacy in female and male C57BL/6J mice, focusing on the amygdala as a potential site of noradrenergic/cholinergic interaction. The antidepressant-like effects of guanfacine were blocked by shRNAmediated knockdown of a2AR in amygdala. Knockdown of the high-affinity $\beta 2 \mathrm{nAChR}$ subunit in amygdala also prevented antidepressant-like effects of guanfacine, suggesting that these behavioral effects require ACh signaling through $\beta 2$-containing $\mathrm{nAChRs}$ in this brain area. Ablation of NE terminals prevented the anxiolytic- and antidepressant-like effects of the nicotinic partial agonist cytisine, whereas administration of the cholinesterase antagonist physostigmine induced a depression-like phenotype that was not altered by knocking down a2AR in the amygdala. These studies suggest that ACh and NE have opposing actions on behaviors related to anxiety and depression and that cholinergic signaling through $\beta 2$-containing nAChRs and noradrenergic signaling through a2a receptors in neurons of the amygdala are critical for regulation of these behaviors.
\end{abstract}

Neuropsychopharmacology (2018) 43:2118-2125; https://doi.org/10.1038/s41386-018-0024-x

\section{INTRODUCTION}

Norepinephrine (NE) is a neurotransmitter essential for stress reactivity, resilience, and arousal, and NE signaling is thought to be dysregulated in several psychiatric disorders [1-3]. Medications targeting the noradrenergic system are used to treat anxiety and depression [4], and recent studies have suggested that guanfacine, an a2A adrenergic receptor agonist (a2AR), could be effective for treating pediatric anxiety disorders [5], as well as stress-induced relapse in cocaine-users [6-9] and in smokers [10]. Animal models have also identified effects of guanfacine on behaviors related to stress response, anxiety, and depression [11, 12].

The ability of guanfacine to decrease stress-induced relapse to smoking suggests that there may be interactions between noradrenergic signaling and signaling through nicotinic acetylcholine receptors ( $\mathrm{nAChRs),} \mathrm{the} \mathrm{primary} \mathrm{targets} \mathrm{for} \mathrm{nicotine} \mathrm{in} \mathrm{the}$ brain. One consequence of chronic nicotine exposure through tobacco smoke is an upregulation of high-affinity $\beta 2$-containing $n A C h R s$ throughout the brain [13]. During withdrawal, as nicotine is cleared from the brain, these nAChRs become available for signaling through the endogenous neurotransmitter acetylcholine $(A C h)$. This increase in cholinergic signaling during tobacco withdrawal may contribute to the increase in symptoms of anxiety and depression observed during acute abstinence [14-16].
Similarly, increasing ACh levels by administering the acetylcholinesterase (AChE) inhibitor physostigmine can induce symptoms of anxiety and depression in control human subjects or in patients with a history of mood disorders $[17,18]$. Blocking AChE activity induces behaviors related to depression, anxiety, and social stress in rodents as well, all of which can be reversed by blocking cholinergic receptors [19]. Thus excessive activation of the cholinergic system increases stress-related behaviors, while blocking cholinergic signaling through its receptors reverses these effects [20].

The basolateral amygdala (BLA) is a critical brain region implicated in anxiety and depression in human subjects and in the mouse [21-23]. Several neurotransmitters, including the noradrenergic and cholinergic systems, converge on the BLA and contribute to its modulation. ACh released in the BLA promotes long-term potentiation of excitatory inputs to the structure, enhances the encoding of fear memory, and delays its extinction [24]. Decreasing $\mathrm{nAChR}$ signaling in the amygdala, either pharmacologically with the $\mathrm{nAChR}$ antagonist mecamylamine or the partial agonist cytisine or genetically by knocking down $\beta 2$ or $\alpha 7$ subunit-containing nAChRs, can induce anxiolyticand antidepressant-like effects in mice and can reverse some of the anxiety- and depression-like symptoms induced by $\mathrm{AChE}$ blockade [25].

${ }^{1}$ Department of Psychiatry, Yale University School of Medicine, 34 Park Street, 3rd Floor Research, New Haven, CT 06508, USA

Correspondence: Marina R. Picciotto (marina.picciotto@yale.edu)

Received: 24 October 2017 Revised: 29 January 2018 Accepted: 1 February 2018

Published online: 22 February 2018 
An extensive body of literature also demonstrates that NE signaling in the amygdala mediates behavioral responses to stress through increased synaptic plasticity [26] and enhanced storage of fear memories [27]. Tricyclic antidepressants and norepinephrine reuptake inhibitors (NRIs) both block reuptake of NE and thus prolong signaling. Noradrenergic fibers preferentially project to cortical and limbic structures, many of which exhibit abnormal glucose and oxygen metabolism [28] that can be partially restored by chronic treatment with tricyclic antidepressants. Thus altering NE signaling in depressed patients can modulate the activity of brain areas and circuits involved in mood regulation, although the precise neural substrates for these antidepressant effects remain unclear.

Both NE and ACh modulate activity in the BLA, as well as other brain regions involved in behaviors related to depression and anxiety. The noradrenergic and cholinergic systems can interact $[29,30]$ and control basic physiological functions such as muscle control, sleep, and blood pressure regulation, and recent studies have investigated the connection between central ACh and NE in the overlapping regulation of depression and addiction [31]. Together, these results highlight the interactions between the cholinergic and noradrenergic systems, and how modulation of either neurotransmitter can contribute to affective behaviors. Thus we investigated whether interactions between ACh and NE in the BLA might be a critical locus for regulation of behaviors related to anxiety and depression.

\section{METHODS}

\section{Animals}

Adult male and female (6-8-week old) C57BL/6J mice were acquired from the Jackson Laboratory (Bar Harbour, Maine, USA) and were housed 5/cage in a vivarium under standard laboratory conditions (temp $21 \pm 2{ }^{\circ} \mathrm{C}, 12: 12$ light-dark cycle, lights on at 7:00 a.m.). Food and water were available ad libitum. Each cage was randomly assigned to one treatment group (15 mice/group at the beginning of the experiments). All tests were conducted between 8 A.M. and 5 p.m. and were preceded by $30 \mathrm{~min}$ habituation to the testing room. After habituation, vehicle or drugs were injected, and animals were allowed an additional 30 min prior to the beginning of behavioral testing to allow drugs to exert their effect and to reduce the stress caused by injection. At least $48 \mathrm{~h}$ were allowed between behavioral tests. All procedures were approved by the Yale University Animal Care and Use Committee and conformed to the standards of the National Institutes of Health guide for the Care and Use of Laboratory Animals.

\section{Drugs}

Drugs were purchased from Sigma Aldrich and dissolved in phosphate-buffered saline (PBS; $0.1 \mathrm{M}, \mathrm{pH}=7.4$ ). Stock solutions were frozen until use and then diluted such that the final solution was injected at $10 \mathrm{ml} / \mathrm{kg}$ of body weight. For acute experiments, drugs were injected $30 \mathrm{~min}$ before testing (or $60 \mathrm{~min}$ for physostigmine), $5 \mathrm{~min}$ apart when two drugs were administered. To induce NE denervation, mice were injected intraperitoneally with the noradrenergic-selective neurotoxin DSP-4 (one injection per day for 3 days). Numerous studies have demonstrated that this neurotoxin induces a profound NE depletion in rodents within 24 $\mathrm{h}$ of injection, which can last for several days $[32,33]$. DSP-4 acts by degrading the axons of NE neurons [32] emanating exclusively from the locus ceruleus (LC) [34]. Interestingly, LC neurons are not fully ablated by DSP-4 and are able to slowly recover over time $[35,36]$. DSP-4 administration terminated $24 \mathrm{~h}$ before the start of behavioral assays.

Concentrations were as follows: guanfacine $(0.15 \mathrm{mg} / \mathrm{kg})$, cytisine $(1.5 \mathrm{mg} / \mathrm{kg})$, physostigmine $(0.25 \mathrm{mg} / \mathrm{kg})$, and DSP-4 $(50$ $\mathrm{mg} / \mathrm{kg})$.
ShRNA design and construction

Two short hairpin RNAs (shRNAs) targeting the mRNA encoding the $\beta 2 \mathrm{nAChR}$ subunit (Chrnb2) were designed, constructed, and validated using previously published methods [37, 38]. Three shRNAs were designed against the mRNA encoding Adra2a (GenBank accession NM_009602.4): $5^{\prime}$ to $3^{\prime}$ : 1. GCTTAAGAATCAAGGTATAGATGA; 2. GCGTCGCATCAAGGCCATCATTGT; and 3. ATGCGCTGGACCTAGAGGAGAGTT. All sequences were checked by BLAST to ensure that no other genomic sequences could be targeted. shRNAs were each ligated into a pAAV-EGFP-shRNA recombinant vector according to previously described protocols $[39,38]$. The plasmid was designed to incorporate enhanced green fluorescent protein (EGFP) to detect viral-mediated gene expression. PCR and DNA sequencing were used to identify positive clones. Control shRNAs were designed with a scrambled targeting sequence that has no known targets in the Mus Musculus genome.

Virus production, purification, and infusion

Adeno-associated virus 2 (AAV2) production was achieved by triple transfection of human embryonic kidney 239 cells with 135 $\mu \mathrm{g}$ each of pAAV-shRNA, pHelper and pAAV-RC plasmids using the standard calcium phosphate method as described previously $[37,38,40]$. Approximately $72 \mathrm{~h}$ post transfection, cells were harvested, pelleted, and suspended in freezing buffer $(0.15 \mathrm{M} \mathrm{NaCl}$ and $50 \mathrm{mM}$ Tris, $\mathrm{pH}$ 8.0). Cells were then lysed by repeating three freeze-thaw cycles (tubes were moved between an ethanol/dry ice bath and a $42{ }^{\circ} \mathrm{C}$ water bath) and digested by incubating with Benzonase $\left(50 \mathrm{U} / \mathrm{ml}\right.$ final) for $30 \mathrm{~min}$ at $37^{\circ} \mathrm{C}$. All remaining cell residues were removed by centrifuging at $37,000 \times g$ for $20 \mathrm{~min}$. The clarified lysate was collected and added to a centrifuge tube containing a $15,25,40$, and $60 \%$ iodixanol gradient and centrifuged at $50,000 \times \mathrm{g}$ for $200 \mathrm{~min}$ at $10^{\circ} \mathrm{C}$. The $40 \%$ fraction was extracted, diluted in PBS-MK $(1 \times \mathrm{PBS}, 1 \mathrm{mM} \mathrm{MgCl}, 2.5 \mathrm{mM}$ $\mathrm{KCl}$ ), concentrated, and purified with a Centricon Plus-20,100 K filter column.

\section{Surgical procedures}

To knockdown (KD) Adra2 and Chrna2 expression in the amygdala, shRNA-carrying viral vectors were infused with a stereotaxic frame mounted with $5 \mu \mathrm{l}$ Hamilton syringes under $2 \%$ Isoflurane anesthesia. The infusions were bilateral $(0.5 \mu \mathrm{l}$ per side) with the following coordinates (from Bregma): Anterior/ Posterior $=-1.8 \mathrm{~mm}$; Lateral $= \pm 3.4 \mathrm{~mm}$; Dorsal/Ventral $=-5.2$ $\mathrm{mm}$. The infusion rate was $\sim 0.1 \mu \mathrm{l} / \mathrm{min}$, and the needle was then left in place for an additional $5 \mathrm{~min}$ to allow for diffusion. Control animals received a scrambled shRNA ( $\mathrm{Scr}$ ), with no known target in the mouse genome. Infectivity and location of the virus was visualized by GFP expression. After viral infusion, animals were allowed to recover for 3 (for a2A) to 5 (for $\beta 2 \mathrm{nAChR}$ ) weeks to provide sufficient time for infection and KD to take place before testing.

\section{Validation of KD}

$\beta 2 \mathrm{nAChR} K \mathrm{KD}$ was previously validated [25, 37]. Tracers and antibodies available to detect a2A receptors (a2AR) can crossreact with other a2 adrenergic receptors making it necessary to evaluate mRNA levels to detect specific KD of the a2AR subtype. Further, a2AR expressed on presynaptic terminals of neurons projecting to the amygdala are not knocked down using this strategy (because AAV2 only injects cell bodies), so evaluation of mRNA, also present largely in cell bodies, would be a more precise measure of KD efficiency. Further, because a2AR is strongly expressed at higher levels in the hippocampus than in the amygdala, we used this tissue to achieve the highest signalto-noise ratio for KD validation. Therefore, we used real-time PCR (qPCR) of a2AR mRNA following AAV2-shRNA infusion into the hippocampus to evaluate the efficacy of a2AR KD in vivo. AAVshRNA or AAV-SCR ( $n=5$ per group) were infused into the 
A
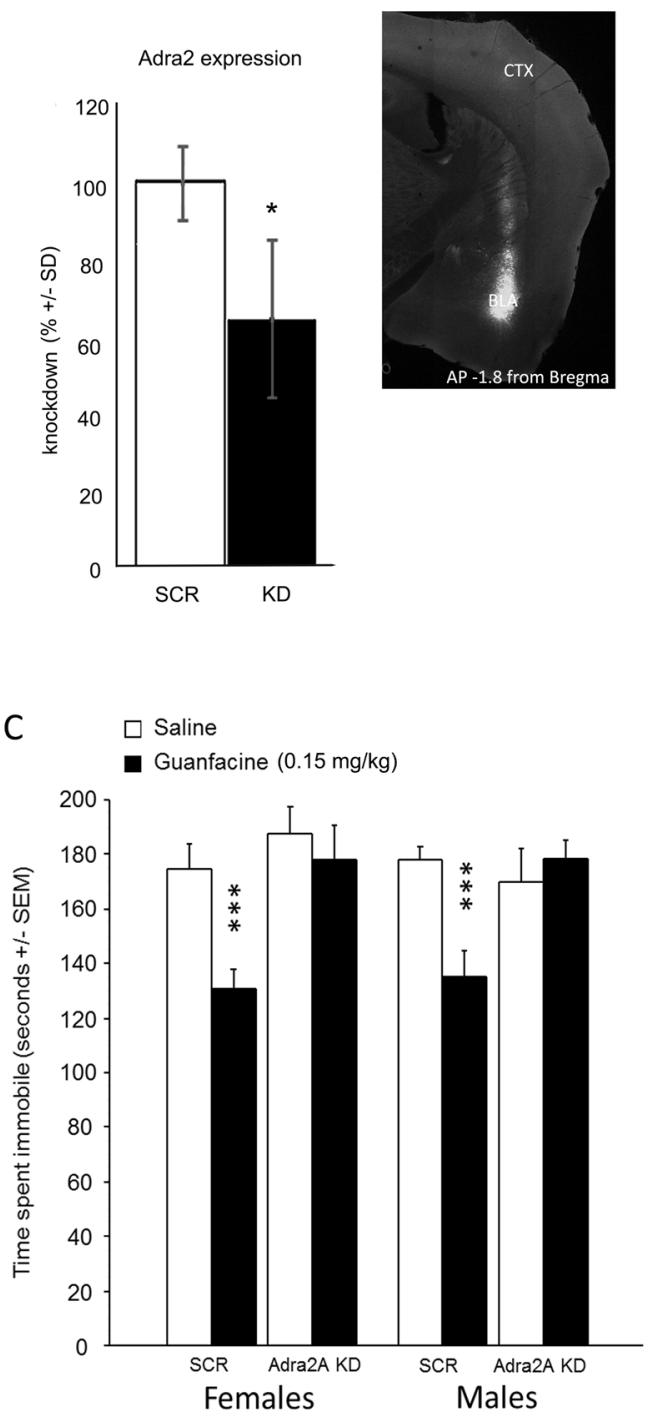

B

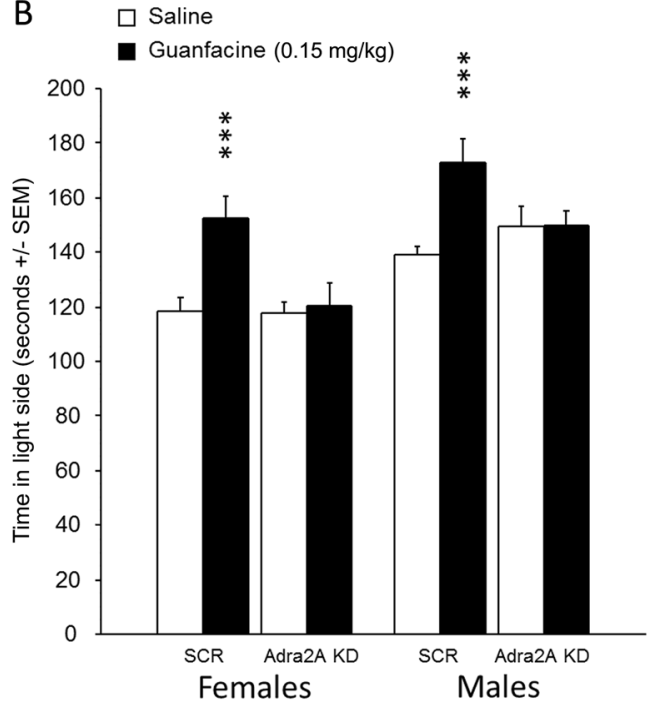

D

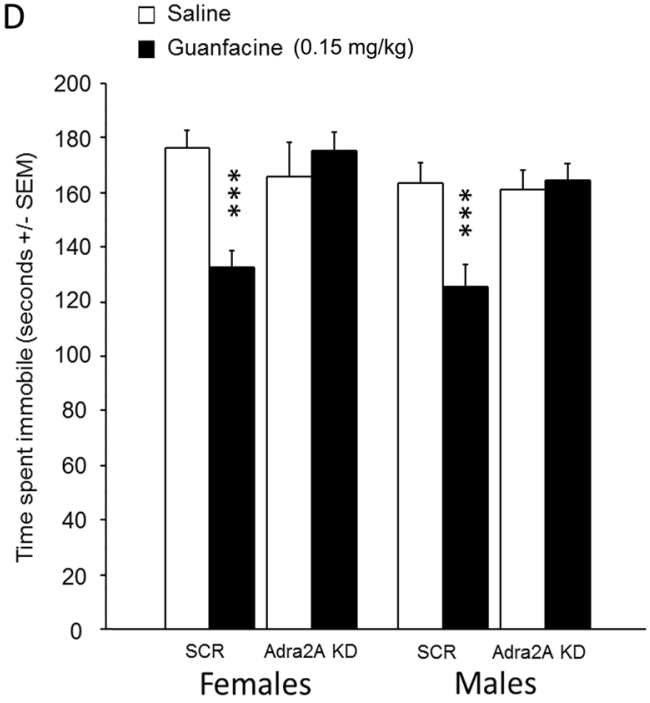

Fig. 1 Real-time PCR of Adra2 mRNA following knockdown (measured in the hippocampus, see Methods for details (a). Confocal images show expression of GFP after infusion of shRNA-carrying AAV (anteroposterior from Bregma: $-1.8 \mathrm{~mm}$; BLA basolateral amygdala, CTX cortex). Effect of $\alpha 2 \mathrm{a}$ adrenergic receptor knockdown in the amygdala combined with guanfacine injection in tests of anxiolytic (light-dark box) and antidepressant efficacy (forced swim and tail suspension). Mice were injected i.p. with either guanfacine $(0.15 \mathrm{mg} / \mathrm{kg})$ or saline $(0.1 \mathrm{M}, \mathrm{pH} 7.3)$, 30 min prior to testing. Time spent in the light side during the light-dark box (b). Time spent immobile in the tail suspension test (c) and forced swim test (d). $N=5$ per group for real-time PCR; $N=10-15$ per group for behavioral assays. ${ }^{*} p<0.05{ }^{* * *} p<0.001$. Real-time PCR data are expressed as mean $\pm \mathrm{SD}$; behavioral data are expressed as mean $\pm \mathrm{SEM}$

hippocampus of C57BL6/J mice for KD validation. Mice were sacrificed 5 weeks after surgery and punches were dissected from each hippocampus. RNA extraction was performed using the RNeasy Lipid Tissue Mini Kit (Qiagen) according to the manufacturer's instructions. A Quantitect Reverse Transcription Kit (Qiagen) was used for reverse transcription to generate CDNA and was quantified by real-time PCR using a StepOne Plus Thermal Cycler by qPCR with SYBR Green (Thermo Fisher Scientific). The efficiency of the following primers was determined:

Forward: GGAATCATGGCTGTGGAGAT

Reverse: TAGGCACAGGGGAAAATGAG.

After normalization to the TATA box-binding protein and glyceraldehyde 3-phosphate dehydrogenase, and detection of GFP to confirm that punched regions had been infected by the virus, qPCR results confirmed that the expression of adra2a mRNA was decreased by $235 \%$ in hippocampal punches from mice infused with shRNAs targeting the a2a receptor mRNA (with multiple iterations of randomized comparisons (REST software for gene quantification, Qiagen), $p<0.05)$. Of note, glial cells do not get infected with AAV2 and contribute to mRNA levels in the sample (Fig. 1a).

Behavioral assays

Light/dark test (LDT). The testing chamber comprised a twocompartment box connected by an opening, with one covered dark compartment and a second light compartment illuminated by a $60 \mathrm{~W}$ bulb ( 100 lux). Mice were placed into the light compartment facing the wall and the time to cross into the dark compartment was recorded. After the first cross, time in the dark side and the number of transitions between compartments was recorded for $6 \mathrm{~min}$. 
A

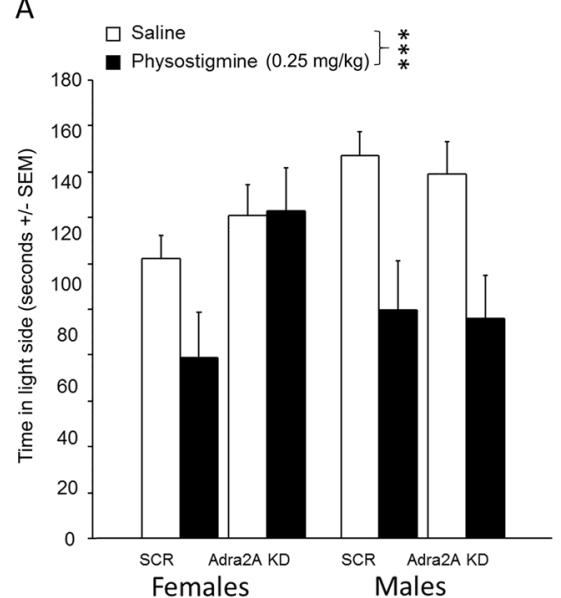

B

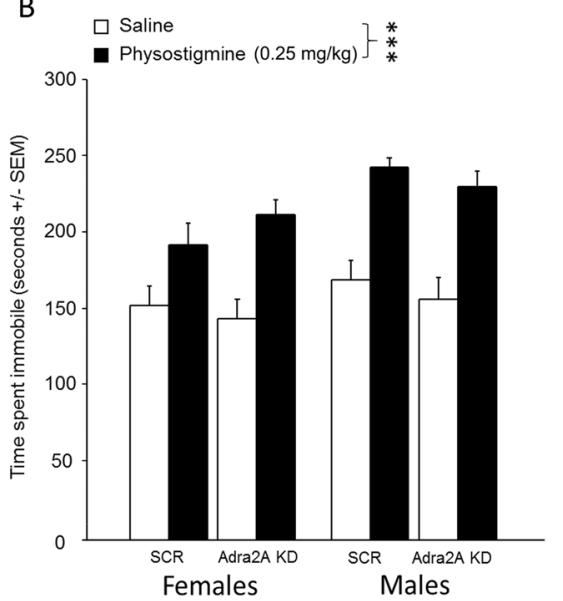

C

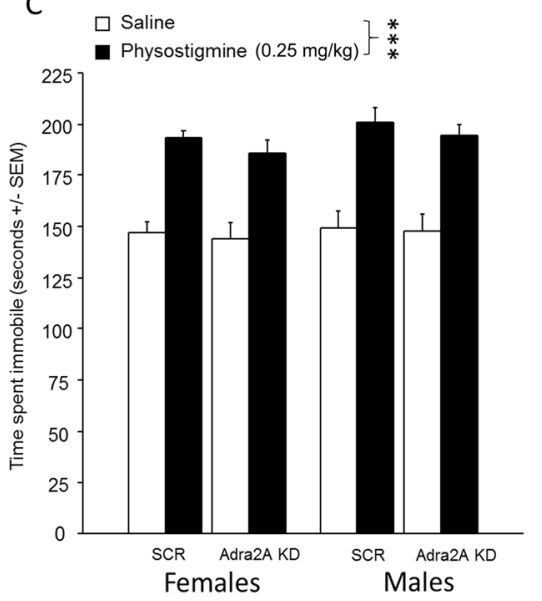

Fig. 2 Effect of $\alpha 2$ a adrenergic receptor knockdown in the amygdala following administration of the cholinesterase inhibitor physostigmine in tests of anxiolytic (light-dark box) and antidepressant efficacy (forced swim and tail suspension). Mice were injected i.p. with either with physostigmine $(0.25 \mathrm{mg} / \mathrm{kg})$ or saline, $60 \mathrm{~min}$ before testing. Time spent in the light side during the light-dark box (a). Time spent immobile in the tail suspension test (b) and forced swim test (c). $N=10-15$ per group. ${ }^{* * *} p<0.001$. All data are expressed as mean \pm SEM

Tail suspension test (TST). Mice were gently suspended by a paper clip taped to the last $5 \mathrm{~mm}$ of their tail for $6 \mathrm{~min}$. Mice were tested one cage at a time and behavior was filmed. Videos were analyzed by a trained rater blind to condition.

Forced swim test (FST). Each mouse was placed in a 4-liter beaker filled with water maintained at room temperature for $15 \mathrm{~min}$. Twenty four hours later, the same procedure was repeated for 5 min. Time spent immobile was recorded over the $5 \mathrm{~min}$ of the second test. Mice were tested one cage at the time and behavior was filmed. Videos were later analyzed by a trained rater blind to condition.

Locomotor activity. Mice were placed in a clean cage $(48 \times 22 \times$ $18 \mathrm{~cm}^{3}$ ) with no bedding for $30 \mathrm{~min}$ in a brightly lit room. Beam breaks (Optomax) were used as an index of locomotor activity.

\section{Statistical analyses}

In dose-response experiments, comparison of mean values between treatment groups was evaluated using analysis of variance with "drug(s)", "knockdown", and "sex" as betweensubject factors. Post hoc analyses were used when appropriate with Fisher's least square deviation when using pharmacological compounds together, or Bonferonni corrections in other designs. KD efficacy was quantified using the REST 2009 software (Qiagen). $P$ was set at 0.05 .

\section{RESULTS}

a2AR in the amygdala are required for guanfacine's effects on anxiety- and depression-like behaviors in male and female mice We first knocked down a2A receptors (the main receptor for guanfacine) to determine whether the amygdala is a critical locus for the effects of guafacine related to anxiety- and depression-like behaviors (Fig. 1).

In the LDT (Fig. 1b), a measure of anxiety-like behavior, there was an interaction between a2AR KD and guanfacine treatment $(F$ $(1,78)=23.7, p<0.001)$ for the time spent in the light side of the testing chamber, with an overall sex effect $(F(1,78)=7.1, p=$ $0.0094)$ but no significant interaction $(f<1)$. Post hoc analyses indicated that both male and female mice showed an increase in time spent in the light compartment when administered guanfacine $(p s<0.01)$, but this effect was not observed after KD of a2AR in the amygdala ( $p s<0.2$ ).
A similar pattern was observed in the TST (Fig. 1c) and FST (Fig. $1 d)$ assays of antidepressant efficacy, with an interaction between $\mathrm{KD}$ and guanfacine treatment $(F(1,72)=22.3, p<0.001$ and $F(1$, $72)=23.0, p<0.001)$. Post hoc analyses show an increase in time spent immobile for both tests after guanfacine administration in mice of both sexes (all $p s<0.001$ ), while a2AR KD animals did not respond to guanfacine administration (all $p s>0.4$ ). This suggests that a2AR expression in amygdala neurons is required for the effect of guanfacine in tests of anxiolytic- and antidepressant-like behaviors.

No significant differences in locomotion were observed as a result of a2AR KD or any pharmacological treatments $[F(1106)=$ $0.29, p=0.5873$ (supp. Figure 1)]. No sex differences were observed in behaviors measured by these tests $(F(1106)=0.598$, $p=0.4412$ ).

Blocking ACh degradation with physostigmine induces anxietyand depression-like behaviors that are not altered by a2AR KD in the amygdala

Because we previously showed that guanfacine can reverse the effects of physostigmine, we determined whether blocking a2A receptors genetically could prevent the effects of physostigmine on anxiety- and depression-like behaviors (Fig. 2). Mice administered physostigmine showed an overall treatment effect in all tests (LDT, Fig. 2a: $F(1,94)=13.5, p<0.001$ ); TST, Fig. 2b: $F(1,94)=$ 57.6, $p<0.001)$; FST, Fig. 2c; $F(1,94)=13.9, p<0.001)$, with no interaction with a2AR KD or sex (all $F s<1$ ), suggesting that the effect of physostigmine is not altered by decreasing a2AR expression in amygdala neuronal cell bodies.

Depletion of NE with DSP-4 reduces the anxiolytic- and antidepressant-like effects of the nicotinic partial agonist cytisine We then determined whether NE was critical for the effects of a drug targeting nAChRs (Fig. 3). We tested the nicotinic partial agonist cytisine on anxiety- and antidepressant-like effects after depleting NE with the neurotoxin DSP-4. In the LDT (Fig. 3a), there was an overall interaction between cytisine and DSP-4 treatments $(F 1,70)=23.2, p<0.001)$ but not with $\operatorname{sex}(F<1)$. Post hoc analyses illustrated this interaction and showed that both male and female mice spent significantly more time in the light side of the LDT chamber when administered cytisine, ( $p=$ 0.002 and $p=0.001$, respectively), as was expected based on previous studies, but this effect was not significant after DSP-4 treatment. 
A

$$
\begin{aligned}
& \square \text { saline + saline } \\
& \square \text { saline + cytisine }(1.5 \mathrm{mg} / \mathrm{kg}) \\
& \square \text { DSP4 }(50 \mathrm{mg} / \mathrm{kg})+\text { saline } \\
& \square \text { DSP4 }(50 \mathrm{mg} / \mathrm{kg})+\text { cytisine }(1.5 \mathrm{mg} / \mathrm{kg})
\end{aligned}
$$

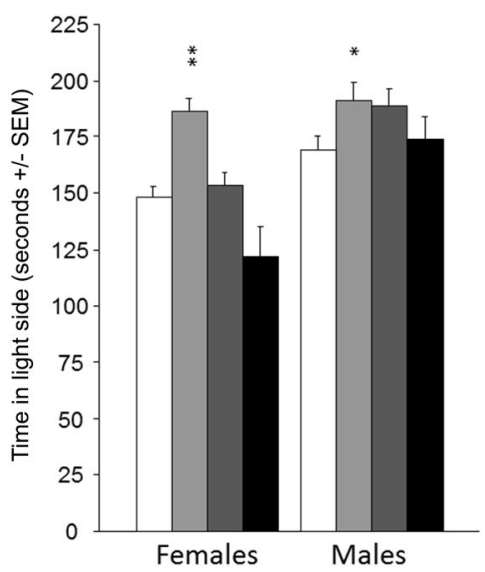

\section{B}

$$
\begin{aligned}
& \square \text { saline + saline } \\
& \square \text { saline + cytisine }(1.5 \mathrm{mg} / \mathrm{kg}) \\
& \square \text { DSP4 }(50 \mathrm{mg} / \mathrm{kg})+\text { saline } \\
& \text { DSP4 }(50 \mathrm{mg} / \mathrm{kg})+\text { cytisine }(1.5 \mathrm{mg} / \mathrm{kg})
\end{aligned}
$$

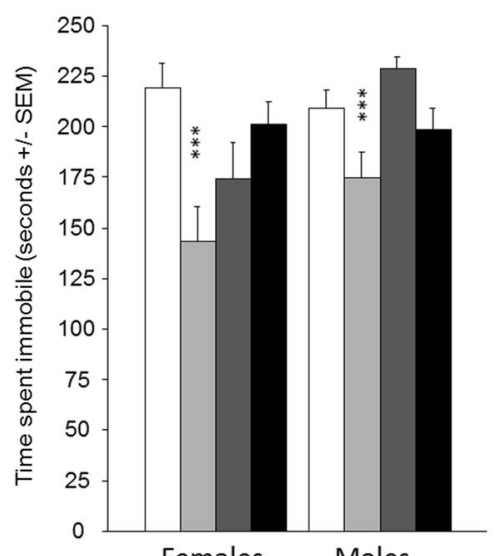

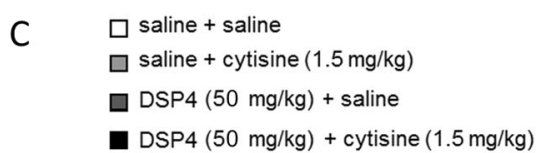

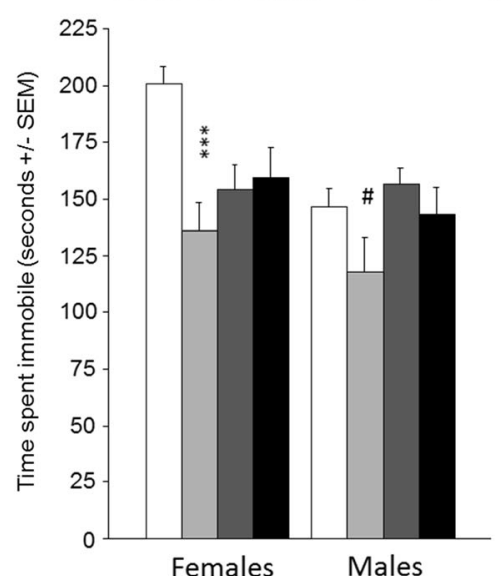

Fig. 3 Effect of the nicotinic partial agonist cytisine $(1.5 \mathrm{mg} / \mathrm{kg}, 30 \mathrm{~min}$ prior to testing) or saline $(0.1 \mathrm{M}, \mathrm{pH} 7.3)$ in tests of anxiolytic (light-dark box) and antidepressant efficacy (forced swim and tail suspension) following norepinephrine depletion with the neurotoxin DSP-4. Time spent in the light side during the light-dark box (a). Time spent immobile in the tail suspension test (b) and forced swim test (c). $N=10-12$ per group. $\# p<0.1 ;{ }^{*} p<0.05 ;{ }^{* *} p<0.01,{ }^{* * *} p<0.001$. All data are expressed as mean \pm SEM
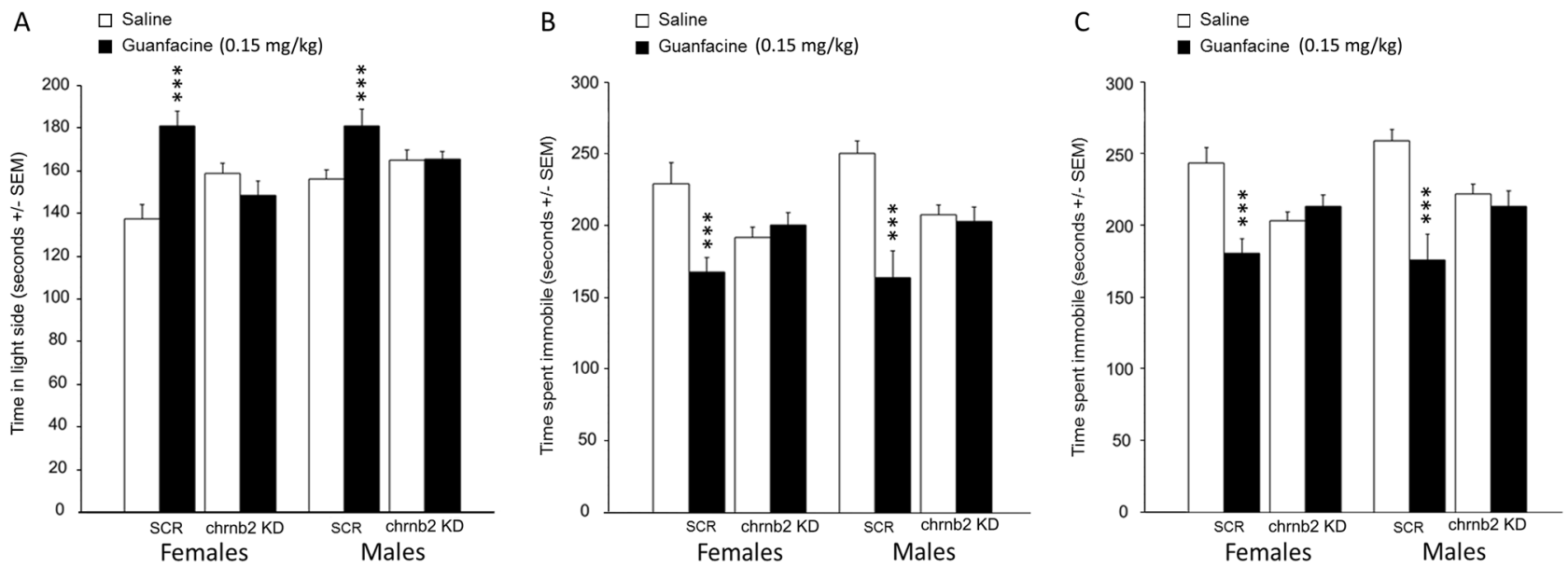

Fig. 4 Effect $\beta 2$ nicotinic acetylcholine receptor subunit knockdown in the amygdala combined with guanfacine injection in tests of anxiolytic (light-dark box) and antidepressant efficacy (forced swim and tail suspension). In all tests, mice were administered either the $\alpha 2 \mathrm{a}$ adrenergic agonist guanfacine $(0.15 \mathrm{mg} / \mathrm{kg})$ or saline $(0.1 \mathrm{M}, \mathrm{pH} 7.3), 30 \mathrm{~min}$ prior to testing. Time spent in the light side during the light-dark box (a). Time spent immobile in the tail suspension test (b) and forced swim test (c). $N=10-15$ per group. ${ }^{* *} p<0.001$. All data are expressed as mean \pm SEM

Similar patterns were observed in the TST (Fig. 3b) and FST (Fig. $3 c)$, with an overall interaction between cytisine and DSP4 treatment (TST: $F(1,68), p=0.004$; FST: $F(1,71)=7.4, p=0.008$ ). Post hoc analyses showed that cytisine administration decreased time spent immobile in mice of both sexes in TST but only in females in FST (TST: male mice, $p=0.02$ and female mice, $p=$ 0.001 ; FST: male mice, $p=0.07$ and female mice, $p=0.003)$. These data suggest that limiting $\mathrm{nAChR}$ ACh signaling with the partial agonist cytisine requires intact NE signaling to induce significant anxiolytic- and antidepressant-like effects in mice.

KD of $\beta 2 n A C h R s$ in the amygdala prevents the anxiolytic- and antidepressant-like effects of guanfacine

Finally, we determined whether guanfacine's effect requires signaling through $\mathrm{nAChRs}$ containing the $\beta 2$ subunit in the amygdala (Fig. 4), since previous studies demonstrated that decreasing signaling through amygdala nAChRs induces anxiolytic- and antidepressant-like phenotypes [25].

In the LDT (Fig. 4a), there was an interaction between $\beta 2 \mathrm{nAChR}$ $\mathrm{KD}$ and guanfacine treatment $(F(1,78)=23.8, p<0.001)$, but no interaction with sex. Further post hoc analyses showed that both male and female control mice increased time spent in the light side after guanfacine treatment (male mice: $p=0.002$; female mice: $p<0.0001$ ), while guanfacine did not alter the time spent in the light side in animals with $\beta 2 \mathrm{nAChR}$ KD (all $p s>0.1$ ).

There was a similar pattern of response to guanfacine in the TST (Fig. 4b) and FST (Fig. 4c), such that there was a significant interaction between $\beta 2 \mathrm{nAChR} \mathrm{KD}$ and guanfacine treatment $(F(1$, $72)=23.3, p<0.0001)$ and $F(1,72), 22.9, p<0.001)$, with no effect of sex $(F<1)$. Post hoc analyses showed that time spent immobile 


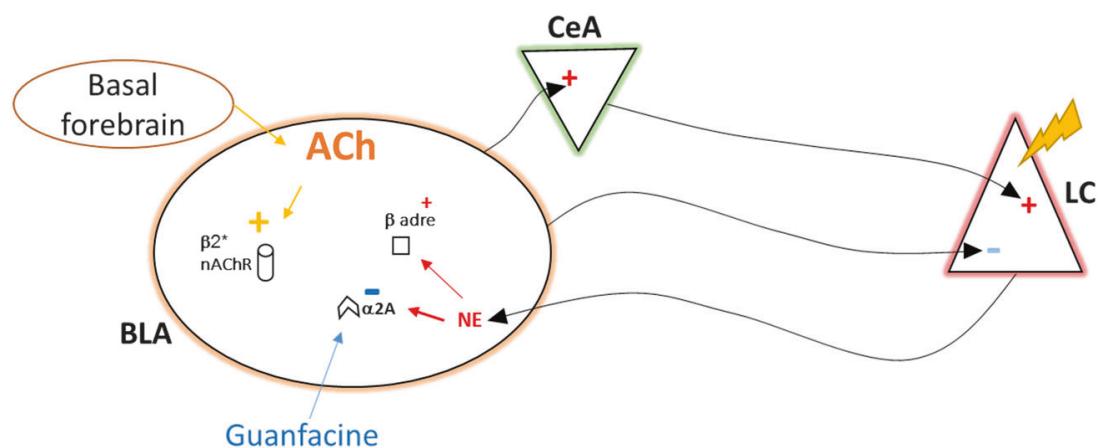

Fig. 5 At baseline, the nucleus basalis provides a substantial acetylcholine (ACh) input to the amygdala, which activates high affinity nicotinic receptors ( $\beta 2 \mathrm{nAChRs)}$ ). Upon exposure to stressful conditions, the HPA axis is stimulated and induces activation of the LC. NE levels increase in the basolateral amygdala (BLA) and activate stimulatory beta adrenergic receptors ( $\beta A R$ ). BLA, in turn, activates the central amygdala (CeA), which feeds back to activate the LC in a positive feedback stress loop. Guanfacine treatment activates Gi-coupled $\alpha 2 A R$, decreasing neuronal activity in amygdala, leading to decreased anxiety- and depression-like behaviors. Similarly, decreasing activity of $\beta 2 \mathrm{nAChRs}$ also decreases activity of BLA neurons, leading to decreased anxiety- and depression-like behaviors. When amygdala nAChR signaling is absent, guanfacine is no longer effective in these behavioral tasks, likely due to the diminished activity of the amygdala, suggesting a dominant role of ACh transmission in amygdala that is permissive for the neuromodulatory role for $\mathrm{NE}$

in both TST and FST was increased following guanfacine administration (TST: male mice, $p<0.0001$; TST: female mice, $p$ $=0.002$; FST: male mice, $p<0.0001$; FST: female mice, $p<0.0001$ ). This effect was abolished in animals following $\beta 2$ nAChR KD in amygdala (all $p \mathrm{~s}>0.2$ ), suggesting that intact $\beta 2 \mathrm{nAChR}$ signaling is required in the amygdala for guanfacine to have an anxiolyticand antidepressant-like effect in mice.

\section{DISCUSSION}

The cholinergic-adrenergic theory of depression hypothesizes that increased cholinergic signaling over noradrenergic tone can lead to depression [41]. This hypothesis is supported by several recent studies showing that human subjects who are actively depressed show increased occupancy of nAChRs by ACh [14-16] and in animal studies in which a depression-like phenotype can be reversed by cholinergic blockade in several brain regions, including the amygdala [19, 25, 42]. These studies support the idea that increased ACh signaling can lead to symptoms of depression.

On the noradrenergic side of the hypothesis, tricyclic and NRI antidepressants block NE reuptake, which likely contributes to a decreased LC activity (as do other classes of antidepressants) [43], contrasting with the increase in LC activity observed in response to chronic stress [44]. Recent clinical trials have shown that the a2aR agonist guanfacine can alleviate some of the negative mood symptoms experienced during drug withdrawal and smoking cessation $[10,45]$ and can also be used to treat pediatric anxiety [5]. The anxiolytic and antidepressant-like effects of guanfacine are also observed in rodents, with similar effects on behavior across sexes, but different patterns of neural activation observed in male and female mice [12].

Several studies have demonstrated that NE signaling can modulate $\mathrm{ACh}$ release through actions on the sympathetic nervous system, as well as in specific brain regions [46], and ACh can also influence NE signaling (reviewed in ref. [47]. The nature of the cross-talk between these neurotransmitter systems and the possible sites of interaction in the brain remain unclear, however. In the current study, we demonstrate that a2AR KD in the amygdala blocks effects of guanfacine in mouse models of anxiety- and depression-like behavior in males and females (Fig. 5). Thus, while previous studies showed that guanfacine could induce sex-specific patterns of neuronal activation but similar behavioral phenotypes [12], the current data indicate that activating a2AR in the amygdala is critical for its anxiolytic- and antidepressant-like effects. It is therefore possible that activation of Gi-coupled a2ARs decreases activity of amygdala neurons important for stress responses, leading to anxiolytic- and antidepressant-like effects of guanfacine.

Because AAV2 only infects neuronal cell bodies and not nerve terminals, only neurons with cell bodies within the amygdala underwent a2AR KD in these studies. Consequently, the effect of guanfacine is not due to negative feedback triggered by autoreceptors located on NE fibers within the amygdala [48] and instead is due to postsynaptic signaling through a2ARs. a2ARs are localized both presynaptically and postsynaptically [49], but the net effect of presynaptic and postsynaptic a2AR activity is likely to be comparable in amygdala. In the BLA, a2ARs are enriched at glutamatergic synapses, upregulated following stressful events, and control synaptic plasticity related to fear memory [50]. Interestingly, a2AR KD on its own did not induce significant effects on the behaviors measured here, which may indicate that NE tone is low at baseline, and a2AR signaling is not engaged. As $\mathrm{NE}$ concentration increases as a result of behavioral or pharmacological challenges and stress, a2ARs, as well as other adrenergic receptor subtypes coupled to Gs proteins, likely become activated, overwhelming the inhibitory effect of Gi signaling through a2ARs [51] and leading to increased activity of amygdala neurons receiving NE input. Guanfacine administration could limit amygdala activity by maintaining a2AR-induced inhibition during exposure to stressors. A similar mechanism has been described in the prefrontal cortex, where low concentrations of $\mathrm{NE}$ preferentially engage $a 2 A R$, while as stress levels and NE concentration increase, $\alpha 1$ and $\beta 1$ adrenergic receptors become activated [52].

The behavioral effects of increased ACh signaling induced by physostigmine administration were not affected by knocking down a2ARs in the amygdala. Since previous studies have shown that systemic guanfacine administration can reverse the behavioral effects of physostigmine in tests of anxiety- and depression-like behavior [12], this suggests that there are additional sites of $\mathrm{ACh} / \mathrm{NE}$ interaction in the brain, that a2ARs on noradrenergic terminals are also important for this effect, or that acute pharmacological activation of ACh signaling can overcome the effects of NE signaling through a2ARs in amygdala. Together, these data show that physostigmine can precipitate anxiety- and depression-like phenotypes independent of a2AR signaling.

Conversely, cytisine, a nicotinic partial agonist that can induce anxiolytic- and antidepressant-like effects in mice [53], is not 
effective in these behavioral tests following NE depletion by the neurotoxin DSP-4 [32]. Cytisine is full agonist at $\beta 4$ and $a 7$ subunitcontaining $\mathrm{nAChRs}$ but can limit cholinergic transmission by directly competing with $A C h$ at $\beta 2$ subunit-containing $n A C h R s$ [54]. DSP-4 treatment alone altered behavior in a subset of behavioral measures of anxiolytic or antidepressant efficacy, although these changes were not statistically significant, so this may contribute, in part, to the absence of behavioral consequences following cytisine treatment. The results did not indicate that a floor effect could completely explain the current results, however. Rather, the data suggest that decreasing cholinergic signaling through $\beta 2$ subunit-containing $n A C h R s$ can only have anxiolytic- and antidepressant-like effects if NE signaling is intact, reinforcing the idea that $\mathrm{ACh}-\mathrm{NE}$ signaling interact to mediate behaviors related to anxiety and depression. One possibility could be that inhibiting ACh signaling can decrease NE release, thereby engaging a2AR signaling over $\beta A R s$ [55], which would be prevented by eliminating NE release.

The most surprising $A C h-N E$ interaction observed in the current study was that KD of the $\beta 2 \mathrm{nAChR}$ subunit in the amygdala abolished the anxiolytic- and antidepressant-like effect of guanfacine in both male and female mice. Because the effects of the $\mathrm{nAChR}$ partial agonist were dependent on an intact NE system, it is possible that $\beta 2 \mathrm{nAChR}$ KD indirectly decreased NE release in amygdala or projecting areas following behavioral challenge (Fig. 5). Only neurons with cell bodies soma in the amygdala would be sensitive to $\beta 2 \mathrm{nAChR} K D$ in the current study; thus any effects on NE release would be due to decreased activity of BLA (as occurs following pharmacological antagonism or $\mathrm{KD}$ of $\beta 2 \mathrm{nAChRs}$ in amygdala $[25,56]$, which could then feedback to the LC and decrease neurotransmitter release from NE neurons (reviewed in ref. [57]. An additional possibility is that signaling in amygdala neurons, either through a cellautonomous or intra-amygdala circuit, is affected synergistically by $n A C h R s$ and a2ARs, so loss of signaling through $\beta 2 n A C h R s$ alters the threshold for NE effects in the structure. Alternatively, because $\beta 2 \mathrm{nAChR}$ KD induces an antidepressant-like effect on its own, the antidepressant-like effects of guanfacine could be masked by a floor effect. However, the degree of immobility following $\beta 2 n A C h R$ KD does not appear to be greater than that induced by guanfacine in wild-type mice, so this seems less likely.

Taken together, the data in this study demonstrate NE-ACh cross-talk in the amygdala mediated through a2ARs and $\beta 2$ nAChRs (Fig. 5). a2ARs in amygdala neurons are required for the behavioral effects of guanfacine in tests of its anxiolytic and antidepressant effects; however, KD of a2ARs in amygdala neurons is not sufficient to prevent the behavioral effects of a systemic increase of $\mathrm{ACh}$ signaling in these tests. Conversely, decreasing ACh signaling with a nicotinic partial agonist is only effective in tests of anxiolytic and antidepressant efficacy if the NE system is intact, indicating that limiting ACh receptor activity may, at least in part, act by decreasing NE tone. Finally, KD of $\beta 2$ nAChRs in amygdala neurons prevented the anxiolytic and antidepressant effects of guanfacine, which suggests that $A C h$ signaling in the amygdala contributes to the ability of a2ARs to alter these behaviors. These data provide new insights into the molecular basis for ACh-NE interactions relevant to anxiety and depression, as well as identifying the amygdala as a critical brain structure underlying the effects of guanfacine in behavioral tasks relevant to anxiolytic and antidepressant efficacy. The results suggest that ACh-NE interactions could be relevant to understanding the etiology of anxiety disorders and depression and provide new possibilities for development of treatments for affective disorders and the mood and anxiety symptoms that can contribute to ongoing substance abuse.

\section{ACKNOWLEDGEMENTS}

\section{FUNDING}

This work was supported by NIH grants DA033945 (ORWH, NIDA, FDA) and MH077681.

\section{ADDITIONAL INFORMATION}

The online version of this article (https://doi.org/10.1038/s41386-018-0024-x) contains supplementary material, which is available to authorized users.

Conflict of interest: The authors declare that they have no conflict of interest.

Publisher's note: Springer Nature remains neutral with regard to jurisdictional claims in published maps and institutional affiliations.

\section{REFERENCES}

1. Glavin GB. Stress and brain noradrenaline: a review. Neurosci Biobehav Rev. 1985;9:233-43.

2. Isingrini E, Perret L, Rainer Q, Amilhon B, Guma E, Tanti A, et al. Resilience to chronic stress is mediated by noradrenergic regulation of dopamine neurons. Nat Neurosci. 2016;19:560-3.

3. Morilak DA, Barrera G, Echevarria DJ, Garcia AS, Hernandez A, Ma S, et al. Role of brain norepinephrine in the behavioral response to stress. Prog Neuropsychopharmacol Biol Psychiatry. 2005;29:1214-24.

4. Caudill MM, Hunter AM, Cook IA, Leuchter AF. The antidepressant treatment response index as a predictor of reboxetine treatment outcome in major depressive disorder. Clin EEG Neurosci. 2015;46:277-84.

5. Strawn JR, Compton SN, Robertson B, Albano AM, Hamdani M, Rynn MA. Extended release guanfacine in pediatric anxiety disorders: a pilot, randomized, placebo-controlled trial. J Child Adolesc Psychopharmacol. 2017;27:29-37.

6. Fox $\mathrm{H}$, Sinha $\mathrm{R}$. The role of guanfacine as a therapeutic agent to address stressrelated pathophysiology in cocaine-dependent individuals. Adv Pharmacol. 2014a;69:217-65.

7. Fox $H$, Sofuoglu M, Sinha R. Guanfacine enhances inhibitory control and attentional shifting in early abstinent cocaine-dependent individuals. J Psychopharmacol (Oxf, Engl). 2015;29:312-23.

8. Gold PW. The organization of the stress system and its dysregulation in depressive illness. Mol Psychiatry. 2015;20:32-47.

9. Sofuoglu M, Rosenheck R, Petrakis I. Pharmacological treatment of comorbid PTSD and substance use disorder: recent progress. Addict Behav. 2014;39:428-33.

10. McKee SA, Potenza MN, Kober H, Sofuoglu M, Arnsten AF, Picciotto MR, et al. A translational investigation targeting stress-reactivity and prefrontal cognitive control with guanfacine for smoking cessation. J Psychopharmacol (Oxf, Engl). 2015;29:300-11.

11. Fox HC, Morgan PT, Sinha R. Sex differences in guanfacine effects on drug craving and stress arousal in cocaine-dependent individuals. Neuropsychopharmacology. 2014b;39:1527-37.

12. Mineur YS, Bentham MP, Zhou WL, Plantenga ME, McKee SA, Picciotto MR. Antidepressant-like effects of guanfacine and sex-specific differences in effects on c-fos immunoreactivity and paired-pulse ratio in male and female mice. Psychopharmacology. 2015;232:3539-49.

13. Staley JK, Krishnan-Sarin S, Cosgrove KP, Krantzler E, Frohlich E, Perry E, et al. Human tobacco smokers in early abstinence have higher levels ofbeta2* nicotinic acetylcholine receptors than nonsmokers. J Neurosci. 2006;26:8707-14.

14. Hannestad JO, Cosgrove KP, DellaGioia NF, Perkins E, Bois F, Bhagwagar Z, et al. Changes in the cholinergic system between bipolar depression and euthymia as measured with [123I]5IA single photon emission computed tomography. Biol Psychiatry. 2013;74:768-76.

15. Saricicek A, Esterlis I, Maloney KH, Mineur YS, Ruf BM, Muralidharan A, et al. Persistentbeta2*-nicotinic acetylcholinergic receptor dysfunction in major depressive disorder. Am J Psychiatry. 2012;169:851-9.

16. Esterlis I, Hannestad JO, Bois F, Sewell RA, Tyndale RF, Seibyl JP, et al. Imaging changes in synaptic acetylcholine availability in living human subjects. J Nucl Med. 2013;54:78-82.

17. Janowsky DS, Overstreet DH. Cholinergic dysfunction in depression. Pharmacol Toxicol. 1990;3:100-11.

18. Risch SC, Cohen RM, Janowsky DS, Kalin NH, Murphy DL. Mood and behavioral effects of physostigmine on humans are accompanied by elevations in plasma beta-endorphin and cortisol. Science. 1980;209:1545-6. 
19. Mineur YS, Obayemi A, Wigestrand MB, Fote GM, Calarco CA, Li AM, et al. Cholinergic signaling in the hippocampus regulates social stress resilience and anxiety- and depression-like behavior. Proc Natl Acad Sci USA. 2013;110:3573-8.

20. Mineur YS, Picciotto MR. Nicotine receptors and depression: revisiting and revising the cholinergic hypothesis. Trends Pharmacol Sci. 2010;31:580-6.

21. Lin LC, Lewis DA, Sibille E. A human-mouse conserved sex bias in amygdala gene expression related to circadian clock and energy metabolism. Mol Brain. 2011;4:18.

22. Tye KM, Prakash R, Kim SY, Fenno LE, Grosenick L, Zarabi H, et al. Amygdala circuitry mediating reversible and bidirectional control of anxiety. Nature. 2011;471:358-62.

23. Clark CP, Brown GG, Archibald SL, Fennema-Notestine C, Braun DR, Thomas LS, et al. Does amygdalar perfusion correlate with antidepressant response to partial sleep deprivation in major depression? Psychiatry Res. 2006;146:43-51.

24. Jiang L, Kundu S, Lederman JD, Lopez-Hernandez GY, Ballinger EC, Wang S, et al. Cholinergic signaling controls conditioned fear behaviors and enhances plasticity of cortical-amygdala circuits. Neuron. 2016;90:1057-70.

25. Mineur YS, Fote GM, Blakeman S, Cahuzac EL, Newbold SA, Picciotto MR. Multiple nicotinic acetylcholine receptor subtypes in the mouse amygdala regulate affective behaviors and response to social stress. Neuropsychopharmacology. 2016;41:1579-87

26. Tully K, Bolshakov VY. Emotional enhancement of memory: how norepinephrine enables synaptic plasticity. Mol Brain. 2010;3:15.

27. Ferry B, Roozendaal B, McGaugh JL. Role of norepinephrine in mediating stress hormone regulation of long-term memory storage: a critical involvement of the amygdala. Biol Psychiatry. 1999:46:1140-52.

28. Drevets WC, Bogers W, Raichle ME. Functional anatomical correlates of antidepressant drug treatment assessed using PET measures of regional glucose metabolism. Eur Neuropsychopharmacol. 2002;12:527-44.

29. Carrier GO, Bishop VS. The interaction of acetycholine and norepinephrine on heart rate. J Pharmacol Exp Ther. 1972;180:31-37.

30. Devore S, Linster C. Noradrenergic and cholinergic modulation of olfactory bulb sensory processing. Front Behav Neurosci. 2012;6:52.

31. Verplaetse $\mathrm{TL}$, Weinberger AH, Smith PH, Cosgrove KP, Mineur YS, Picciotto MR, et al. Targeting the noradrenergic system for gender-sensitive medication development for tobacco dependence. Nicotine Tob Res. 2015;17:486-95.

32. Jonsson G, Hallman H, Ponzio F, Ross S. DSP4 (N-(2-chloroethyl)-N-ethyl-2-bromobenzylamine)--a useful denervation tool for central and peripheral noradrenaline neurons. Eur J Pharmacol. 1981;72:173-88.

33. Ross SB, Renyl AL. On the long-lasting inhibitory effect of $\mathrm{N}$-(2-chloroethyl)-Nethyl-2-bromobenzylamine (DSP 4) on the active uptake of noradrenaline. J Pharm Pharmacol. 1976;28:458-9.

34. Grzanna R, Berger U, Fritschy JM, Geffard M. Acute action of DSP-4 on central norepinephrine axons: biochemical and immunohistochemical evidence for differential effects. J Histochem Cytochem. 1989;37:1435-42.

35. Scullion GA, Kendall DA, Sunter D, Marsden CA, Pardon MC. Central noradrenergic depletion by DSP-4 prevents stress-induced memory impairments in the object recognition task. Neuroscience. 2009;164:415-23.

36. Srinivasan J, Schmidt WJ. Functional recovery of locus coeruleus noradrenergic neurons after DSP-4 lesion: effects on dopamine levels and neuroleptic inducedparkinsonian symptoms in rats. J Neural Transm (Vienna). 2004;111:13-26.

37. Mineur YS, Abizaid A, Rao Y, Salas R, DiLeone RJ, Gundisch D, et al. Nicotine decreases food intake through activation of POMC neurons. Science. 2011;332:1330-2.

38. Hommel JD1, Sears RM, Georgescu D, Simmons DL, DiLeone RJ. Local gene knockdown in the brain using viral-mediated RNA interference. Nature Medicine 2003;9(12):1539-44.
39. Benavides DR, Quinn JJ, Zhong P, Hawasli AH, DiLeone RJ, Kansy JW, et al. Cdk5 modulates cocaine reward, motivation, and striatal neuron excitability. J Neurosci 2007;27(47): 12967-12976

40. Zolotukhin S, Byrne BJ, Mason E, Zolotukhin I, Potter M, Chesnut K, et al Recombinant adenoassociated virus purification using novel methods improves infectious titer and yield. Gene therapy 1999;6(6): 973-985.

41. Janowsky DS, el-Yousef MK, Davis JM, Sekerke HJ. A cholinergic-adrenergic hypothesis of mania and depression. Lancet. 1972;2:632-5.

42. Mineur YS, Mose TN, Blakeman S, Picciotto MR (2017). Hippocampal alpha7 nicotinic $A C h$ receptors contribute to modulation of depression-like behaviour in C57BL/6J mice. Br J Pharmacol. https://www.ncbi.nlm.nih.gov/pubmed/ 28264149

43. West $\mathrm{CH}$, Ritchie JC, Boss-Williams KA, Weiss JM. Antidepressant drugs with dif fering pharmacological actions decrease activity of locus coeruleus neurons. Int $J$ Neuropsychopharmacol. 2009;12:627-41.

44. Morilak DA, Fornal CA, Jacobs BL. Effects of physiological manipulations on locus coeruleus neuronal activity in freely moving cats. I. Thermoregulatory challenge. Brain Res. 1987:422:17-23.

45. Aston-Jones G1, Kalivas PW. Brain norepinephrine rediscovered in addiction research. Biol Psychiatry. 2008;63(11):1005-6.

46. Vizi ES, Ronai A, Harsing LG, Knoll J (1978). Presynaptic modulation by norepinephrine and dopamine of acetylcholine release in the peripheral and central nervous system. In: Jenden DJ, editor. Cholinergic mechanisms and psychopharmacology. Springer US: Boston, MA, pp 587-603.

47. Picciotto MR, Higley MJ, Mineur YS. Acetylcholine as a neuromodulator: cholinergic signaling shapes nervous system function and behavior. Neuron. 2012;76:116-29.

48. Hein L, Altman JD, Kobilka BK. Two functionally distinct alpha2-adrenergic receptors regulate sympathetic neurotransmission. Nature. 1999;402:181-4.

49. Berridge CW, Waterhouse BD. The locus coeruleus-noradrenergic system: modulation of behavioral state and state-dependent cognitive processes. Brain Res Brain Res Rev. 2003;42:33-84

50. Simoes AP, Machado NJ, Goncalves N, Kaster MP, Simoes AT, Nunes A, et al. Adenosine $A 2 A$ receptors in the amygdala control synaptic plasticity and contextual fear memory. Neuropsychopharmacology. 2016;41:2862-71.

51. Buffalari DM, Grace AA. Noradrenergic modulation of basolateral amygdala neuronal activity: opposing influences of alpha-2 and beta receptor activation. $J$ Neurosci. 2007a;27:12358-66.

52. Ramos BP, Arnsten AF. Adrenergic pharmacology and cognition: focus on the prefrontal cortex. Pharmacol Ther. 2007;113:523-36.

53. Mineur YS, Somenzi O, Picciotto MR. Cytisine, a partial agonist of high-affinity nicotinic acetylcholine receptors, has antidepressant-like properties in male C57BL/6J mice. Neuropharmacology. 2007;52:1256-62.

54. Papke RL, Heinemann SF. Partial agonist properties of cytisine on neuronal nicotinic receptors containing the beta 2 subunit. Mol Pharmacol. 1994;45: $142-9$.

55. Buffalari DM, Grace AA. Noradrenergic modulation of basolateral amygdala neuronal activity: opposing influences of alpha- 2 and beta receptor activation. $J$ Neurosci. 2007b:27:12358-66.

56. Mineur YS, Eibl C, Young G, Kochevar C, Papke RL, Gundisch D, et al. Cytisinebased nicotinic partial agonists as novel antidepressant compounds. J Pharmacol Exp Ther. 2009;329:377-86.

57. Samuels ER, Szabadi E. Functional neuroanatomy of the noradrenergic locus coeruleus: its roles in the regulation of arousal and autonomic function part II: physiological and pharmacological manipulations and pathological alterations of locus coeruleus activity in humans. Curr Neuropharmacol. 2008;6:254-85. 